\title{
First-line treatment of hypertension: critical appraisal of potential role of aliskiren and hydrochlorothiazide in a fixed combination
}

\author{
Konstantinos Savvatis' \\ Dirk Westermann' \\ Heinz-Peter Schultheiss ${ }^{\prime}$ \\ Carsten Tschöpe ${ }^{1,2}$ \\ 'Charité Universitätsmedizin \\ Berlin, Department of Cardiology \\ and Pneumonology, Campus \\ Benjamin Franklin, Berlin; ${ }^{2}$ Charité \\ Universitätsmedizin Berlin, Berlin- \\ Brandenburg Center for Regenerative \\ Therapies, Campus Virchow-Klinikum, \\ Berlin, Germany
}

This article was published in the following Dove Press journal: Integrated Blood Pressure Control 30 November 2010

Number of times this article has been viewed

\begin{abstract}
Arterial hypertension is one of the major diseases in the Western world. It is an independent cardiovascular risk factor and is associated with increased morbidity and mortality. Several drug classes have been shown to be effective in the treatment of hypertension. Aliskiren is a direct renin inhibitor and belongs to the class of renin-angiotensin-aldosterone system inhibitors. Several large studies have shown that aliskiren is effective in lowering blood pressure, and equivalent in this respect to the angiotensin-converting enzyme (ACE) inhibitors and the angiotensin receptor-1 blockers (ARBs). Furthermore, aliskiren has a safety and tolerability profile comparable with that of the ARBs and slightly better than that of the ACE inhibitors. From a pathophysiologic perspective, it can be combined with hydrochlorothiazide successfully, because it can block the diuretic-induced increase in plasma renin activity. Its combination with hydrochlorothiazide in a single pill has been investigated and shown to be superior to monotherapy with respect to blood pressure control and improvement in patient compliance with therapy. Further studies are needed to show whether aliskiren and its combination with hydrochlorothiazide is effective in preventing cardiovascular events and mortality when end organ damage is present.
\end{abstract}

Keywords: aliskiren, hydrochlorothiazide, combination, hypertension

\section{Introduction}

Arterial hypertension is one of the most common diseases in the developed world. It is one of the major cardiovascular risk factors for development of coronary heart disease, heart failure, stroke, and chronic kidney disease. In 2000, more than 970 million people worldwide had elevated blood pressure, and this number is expected to have increased by $60 \%$ in $2025 .{ }^{1}$ According to the World Health Organization, arterial hypertension accounts for 7.1 million deaths per year, and this number is expected to rise in the future. ${ }^{2}$

The guidelines of the 7th Joint National Committee on Prevention, Detection, Evaluation and Treatment of High Blood Pressure (JNC 7), as well as those of the European Society of Cardiology and European Society of Hypertension recommend a target blood pressure lower than 140/90 $\mathrm{mmHg}$ in uncomplicated hypertension and lower than 130/80 $\mathrm{mmHg}$ when additional risk factors, such as diabetes or coronary heart disease, are present. ${ }^{3,4}$ Despite these recommendations and the existence of many different antihypertensive drugs, hypertension in the US is only controlled in about $30 \%-60 \%$ of patients, and this rate is much lower in western European countries. ${ }^{5,6}$ At least $75 \%$ of hypertensive patients require combination therapy to achieve current blood pressure goals. ${ }^{7-9}$ Combination of several agents allows for synergistic action
Correspondence: Konstantinos Savvatis Department of Cardiology, Campus Benjamin Franklin, Hindenburgdamm 30, 12200 Berlin, Germany

Tel +4903084452349

Fax +49030 84454648

Email ksavvatis@gmail.com 
and use of lower doses of the individual drugs, leading to a reduction in side effects and improvement of patient compliance. ${ }^{10}$ Therefore, combination treatment as first-line therapy is a logical choice for patients with moderate to severe hypertension.

The renin-angiotensin-aldosterone system (RAAS) plays a crucial role in the pathophysiology of hypertension and cardiovascular diseases. ${ }^{11}$ Drugs that target the RAAS, such as angiotensin-converting enzyme (ACE) inhibitors and blockers of angiotensin receptor-1 (ARBs), are effective in reducing blood pressure, as well as the morbidity and mortality associated with hypertension and cardiovascular diseases. Their low rate of side effects makes them well tolerated and therefore attractive as first-line agents in the treatment of arterial hypertension. ${ }^{12}$ Blockers of the RAAS are widely combined with thiazide diuretics, mainly hydrochlorothiazide, a strategy supported pathophysiologically by the mechanism of action of the two drug classes. Hydrochlorothiazide leads to activation of the RAAS through sodium and water depletion, which limits its antihypertensive effects (Table 1), and its combination with a RAAS blocker potentiates the effects of both agents. ${ }^{13}$

A recent addition to the family of RAAS-blockers is aliskiren, a direct renin inhibitor, now approved for the treatment of hypertension. Several studies have already investigated the effects of aliskiren as monotherapy in lowering blood pressure and in combination with other agents, including calcium channel blockers and hydrochlorothiazide. At present, aliskiren is available as a fixed combination with hydrochlorothiazide in several dose strengths, ie, $150 / 12.5 \mathrm{mg}, 150 / 25 \mathrm{mg}, 300 / 12.5 \mathrm{mg}$, and $300 / 25 \mathrm{mg}$, and is approved as second-line treatment in patients whose blood pressure is not adequately controlled by the individual drugs alone. This review focuses on the efficacy of the combination of aliskiren with hydrochlorothiazide as a potential first-line treatment of hypertension.

\section{Renin-angiotensin-aldosterone inhibitors}

The RAAS is a system of active peptides and enzymes, mainly responsible for fluid and electrolyte homeostasis and vascular tone (see Figure 1). Furthermore, RAAS plays an important role in inflammation, cellular and organ hypertrophy, and fibrosis, and activation of this system is therefore important in the pathophysiology of cardiovascular diseases, including hypertension, myocardial infarction, heart and kidney failure, and stroke. ${ }^{14,15}$

The RAAS cascade begins with renin, an aspartyl protease released by the juxtaglomerular cells of the kidney into the circulation, which consists of two homologous lobes with a cleft in between containing two catalytic aspartic residues. ${ }^{16}$ Renin is produced by proteolytic transformation of its proenzyme, prorenin. ${ }^{17}$ Renin acts on angiotensinogen and converts it to angiotensin I. This is the rate-limiting step of RAAS activation. Angiotensin I is converted to angiotensin II in the lungs through the action of ACE. Traditionally, angiotensin II is considered to be the major effector molecule of the RAAS. Angiotensin II exerts its effects mainly through its Type 1 $\left(\mathrm{AT}_{1}\right)$ receptors in target organs, but several other types of receptors exist, the actions of which are as yet not entirely clear. ${ }^{18}$ Angiotensin II also acts on the adrenal cortex, leading to the release of aldosterone into the circulation.

Blockade of the RAAS using ACE inhibitors and $\mathrm{AT}_{1}$ receptor blockers has been the mainstay of medical treatment for cardiovascular disease for the last two to three decades. ACE inhibitors inhibit the action of ACE and disrupt the conversion of angiotensin I into angiotensin II. ARBs act on $\mathrm{AT}_{1}$ receptors and directly block the actions of angiotensin II on target organs. RAAS inhibition using ACE inhibitors or ARBs has been proven to be effective in reducing elevated blood pressure, preventing and slowing the progression of cardiovascular disease, and reducing the associated morbidity and mortality. ${ }^{19}$

Table I Effects of RAAS blockers and common antihypertensive agents on different RAAS components

\begin{tabular}{llllllll}
\hline Agent & PRC & PRA & Angiotensinogen & Angiotensin I & Angiotensin II & Angiotensin I-7 & Aldosterone \\
\hline B-blockers & $\downarrow$ & $\downarrow$ & - & $\downarrow$ & $\downarrow$ & $\uparrow$ & $\downarrow$ \\
Calcium antagonists & $\uparrow$ & $\uparrow$ & $\downarrow$ & $\uparrow$ & $\uparrow$ & $\uparrow$ & $\uparrow$ \\
Diuretics & $\uparrow$ & $\uparrow$ & $\downarrow$ & $\uparrow$ & $\downarrow$ & $\uparrow$ & $\downarrow$ \\
ACEi & $\uparrow$ & $\uparrow$ & $\downarrow$ & $\uparrow$ & $\uparrow$ & $\downarrow$ & $\downarrow$ \\
ARBs & $\uparrow$ & $\uparrow$ & $\downarrow$ & $\uparrow$ & $\downarrow$ & $\downarrow$ & $\downarrow$ \\
Aliskiren & $\uparrow \uparrow$ & $\downarrow$ & - & $\downarrow$ & $\downarrow$ & $\downarrow$ \\
Aliskiren-HCTZ & $\uparrow \uparrow \uparrow$ & $\downarrow$ & - & $\downarrow$ & $\downarrow$ & $\downarrow$ \\
\hline
\end{tabular}

Abbreviations: $\mathrm{ACEi}$, angiotensin-converting-enzyme inhibitors; ARB, angiotensin receptor blocker; HCTZ, hydrochlorothiazide; PRC, plasma renin concentration; PRA, plasma renin activity; RAAS, renin-angiotensin-aldosterone system. 


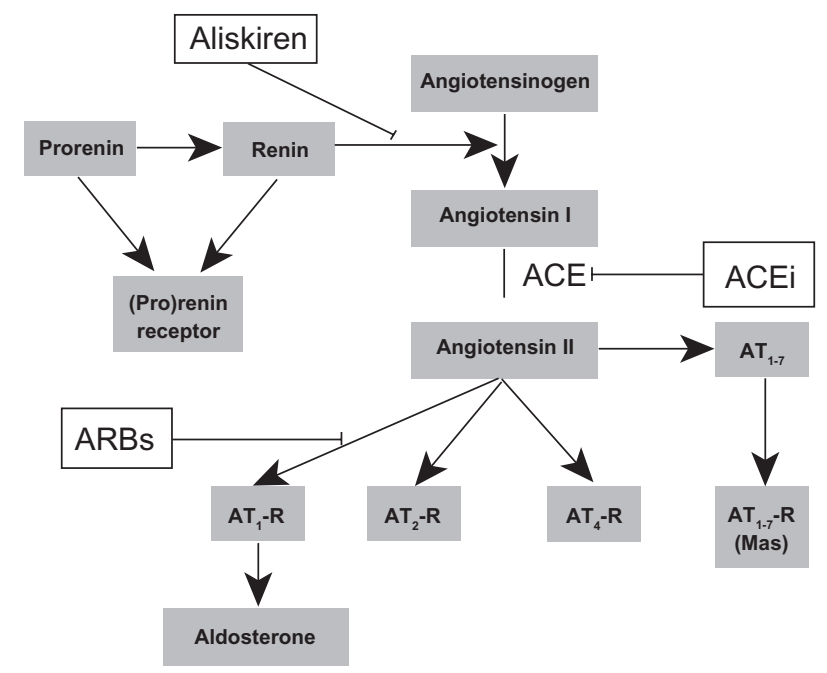

Figure I Schematic illustration of the RAAS and the sites of its blocking for existing RAAS blockers. Shown also are the alternative pathways, which are possibly activated through increase of the different components of the RAAS due to the actions of RAAS blocking agents (see also Table I). Increased renin concentration in the blood can lead to stimulation of the (pro)renin receptor, which leads to intracellular activation of apoptosis, hypertrophy, and fibrosis pathways. Increase of angiotensin II and its metabolites leads to stimulation of alternative receptors which have different effects on vasoconstriction, endothelial function, hypertrophy, and inflammation.

Abbreviations: $A C E i$, angiotensin-converting-enzyme inhibitor; $A R B$, angiotensinreceptor blocker; AT-R, angiotensin receptor.

However, after some months of treatment with ACE inhibitors, levels of angiotensin II in the blood start to rise again, which is known as the "angiotensin escape phenomenon". ${ }^{20}$ Furthermore, both ACE inhibitors and ARBs lead to a compensatory increase in plasma renin concentration and plasma renin activity. ${ }^{21}$ An increase in plasma renin activity may ultimately lead to increased angiotensin II production, which, in turn, may act on receptors other than the $\mathrm{AT}_{1}$ receptor, with potentially harmful effects. However, the exact clinical importance of this phenomenon remains unknown.

Aliskiren is the latest member of the RAAS blocker class of drugs. It acts directly on renin and inhibits its action, thereby blocking the activation of RAAS and the production of angiotensin II directly at its rate-limiting step. ${ }^{22}$ Aliskiren binds the active site of renin and inhibits its catalytic activity. The action of aliskiren at this early upstream step has the potential to block the action of angiotensin more effectively than the other known RAAS blockers.

\section{Aliskiren-hydrochlorothiazide: Pharmacokinetics and pharmacodynamics}

Aliskiren is the first orally available direct nonpeptide renin inhibitor. Its bioavailability after oral administration is $2.6 \%$, with a maximum plasma concentration reached within 1-3 hours after a single oral dose. ${ }^{23}$ Steady-state plasma concentration is reached after 7-8 days of daily administration. Plasma concentration is linearly related to dose in the range of $40-640 \mathrm{mg} /$ day. Its half-life in plasma is $23-40$ hours, thus enabling single daily dosing. ${ }^{24}$ The majority $(90.9 \%)$ of aliskiren is excreted via the biliary/fecal route in healthy subjects after a single dose of $300 \mathrm{mg}$, while $0.6 \%$ of the drug is collected in the urine. ${ }^{25}$ No dose modification needs to be made in the presence of renal or liver disease, and the pharmacokinetics are similar in the common ethnic groups. Aliskiren is not metabolized by cytochrome P450, and therefore has few interactions with other drugs metabolized by this enzyme.

Aliskiren decreases blood pressure mainly by reducing angiotensin II levels. A study in healthy normotensive volunteers showed that aliskiren decreased plasma renin activity in a dose-dependent manner after a single oral dose in the $40-600 \mathrm{mg} /$ day range. Angiotensin I and II decreased accordingly, while plasma renin concentration increased. ${ }^{26}$ In another small study in 12 healthy mildly sodium-depleted volunteers, single oral doses of aliskiren $300 \mathrm{mg}$ decreased plasma renin activity, as well as angiotensin I and II levels in the blood for 48 hours, and reduced urinary aldosterone excretion. Of note, this reduction was stronger and more durable than that of valsartan $160 \mathrm{mg}$. However, aliskiren also induced a greater increase in plasma renin concentration than valsartan. ${ }^{27}$ Increased plasma renin concentration occurs to a greater extent with aliskiren than with other $\mathrm{ACE}$ inhibitors and ARBs, and might be an important issue because prorenin and renin have been shown to stimulate the (pro)renin receptor and induce fibrosis, apoptosis, and organ hypertrophy in experimental disease models.$^{28}$ However, the clinical significance of this finding remains unclear.

Plasma renin activity remains suppressed for up to one month after discontinuation of aliskiren, suggesting that the action of aliskiren may persist for far longer than the drug half-life. Interestingly, this effect is associated with lower blood pressure after discontinuation of the drug. ${ }^{29}$

The bioavailability of oral hydrochlorothiazide is high, ranging between $50 \%$ and $80 \%$. It reaches its maximal blood concentration after 1.0-2.5 hours, and has a half-life of 6-19 hours. Hydrochlorothiazide is not metabolized, and $95 \%$ is excreted in the urine. ${ }^{30}$

Hydrochlorothiazide induces activation of the RAAS mainly via sodium and water depletion, leading to increased plasma renin concentration and plasma renin activity, and therefore angiotensin II production. ${ }^{31}$ Increased plasma renin 
concentration and plasma renin activity is further potentiated when hydrochlorothiazide is combined with an ACE inhibitor or ARB. However, aliskiren was able to suppress plasma renin activity when combined with hydrochlorothiazide $25 \mathrm{mg}$ /day in a study of hypertensive obese patients. ${ }^{32}$ Interestingly, aliskiren also decreases plasma renin activity when combined with other agents known to increase plasma renin activity, including ACE inhibitors and ARBs. ${ }^{27}$

\section{Use of aliskiren-hydrochlorothiazide in hypertension}

Successful use of aliskiren as monotherapy in hypertension has been demonstrated in several studies, and has been extensively reviewed elsewhere. ${ }^{33-35}$ Doses of $150-300 \mathrm{mg}$ once daily have been shown to have similar antihypertensive effects as comparable doses of ACE inhibitors and ARBs. ${ }^{35}$ Interestingly, the antihypertensive effects of aliskiren lasted surprisingly longer than its half-life in blood and persisted for a month after discontinuation of the drug in a study by Andersen et al. ${ }^{29}$ This observation is confirmed by a meta-analysis of eight studies showing that stopping treatment with aliskiren does not lead to a paradoxical increase in blood pressure. ${ }^{36}$

In a placebo-controlled study of 455 Japanese patients with hypertension and a mean sitting diastolic blood pressure of 95-110 $\mathrm{mmHg}$, aliskiren in doses of 75, 150, and $300 \mathrm{mg}$ lowered blood pressure in a dose-dependent manner. Interestingly, after correcting for placebo, the reduction in systolic and diastolic blood pressure was $5.7 / 4 \mathrm{mmHg}$, $5.9 / 4.5 \mathrm{mmHg}$, and $11.2 / 7.5 \mathrm{mmHg}$, respectively, indicating a rather small effect. ${ }^{37}$

Several other studies have compared different doses of aliskiren with the ARBs, irbesartan, losartan, and valsartan, as well as valsartan-hydrochlorothiazide and valsartan-aliskiren combinations. ${ }^{38-40}$ In all studies, aliskiren was effective in the lowering of blood pressure compared with placebo and to a similar extent with comparable doses of the ARBs tested. Furthermore, the combination of valsartan-aliskiren had a stronger antihypertensive effect than monotherapy, and was as effective as the valsartan-hydrochlorothiazide combination. These findings were confirmed in a meta-analysis showing that aliskiren is as effective for blood pressure reduction as the ACE inhibitors and ARBs. ${ }^{35}$

Hydrochlorothiazide is the most commonly prescribed antihypertensive drug in the US, and remains the drug of choice for uncomplicated hypertension in the JNC 7 recommendations. However, the most commonly prescribed doses of hydrochlorothiazide are 12.5 and $25 \mathrm{mg}$. Surprisingly, all the major studies were performed using higher hydrochlorothiazide doses or hydrochlorothiazide in combination with other antihypertensive agents, so little or no evidence exists for the efficacy of low-dose hydrochlorothiazide in hypertension and cardiovascular disease. The Antihypertensive and Lipid-Lowering Treatment to Prevent Heart Attack Trial (ALLHAT), one of the major studies showing equivalent efficacy of diuretics and other antihypertensives, was performed with chlorthalidone, which seems to be more effective than hydrochlorothiazide. ${ }^{41,42}$ Furthermore, hydrochlorothiazide at higher doses whereby its efficacy might be comparable with that of other antihypertensives, shows many adverse effects, including electrolyte imbalance (hypokalemia, hyponatremia), insulin resistance, and hyperuricemia, making it inappropriate as monotherapy. ${ }^{43}$ However, low-dose hydrochlorothiazide remains effective in lowering blood pressure, and from a pathophysiologic perspective, combines well with the RAAS inhibitors, including aliskiren.

Several trials have investigated the use of aliskiren and hydrochlorothiazide alone and in combination for treatment of hypertension (Table 2). In the largest trial to date, Villamil et al investigated the effects of aliskiren and hydrochlorothiazide in 2776 patients with mild hypertension and mean sitting diastolic blood pressure 95-109 $\mathrm{mmHg}$. Aliskiren was used as monotherapy in doses of 75,150 , and $300 \mathrm{mg}$ once daily, hydrochlorothiazide in doses of $6.25,12.5$, and $25 \mathrm{mg}$, and their combination included all possible doses except for the aliskiren-hydrochlorothiazide combination of 300/6.25 mg. The study was of double-blind, randomized, placebocontrolled design and of eight weeks' duration. Both drugs reduced blood pressure significantly compared with placebo, and interestingly, to the same extent for comparable doses of aliskiren and hydrochlorothiazide. Combination of the drugs lowered both diastolic and systolic blood pressure to a greater extent than either drug used alone. The response rates were also higher with the aliskiren-hydrochlorothiazide combination. Increased plasma renin activity and hypokalemia rates seen with hydrochlorothiazide monotherapy were reversed by addition of aliskiren, while the risk of hypokalemia in the combination groups was only slightly higher than with placebo. ${ }^{31}$ Post hoc analysis of the data showed that most of the dose combinations of aliskiren-hydrochlorothiazide were also superior to monotherapy in individuals with Stage 2 hypertension (mean sitting systolic blood pressure $>160 \mathrm{mmHg}$ ). ${ }^{44}$

In a study of 489 obese hypertensive patients already treated with hydrochlorothiazide $25 \mathrm{mg}$, Jordan et al examined the antihypertensive effects of the addition of aliskiren $300 \mathrm{mg}$, irbesartan $300 \mathrm{mg}$, or amlodipine $10 \mathrm{mg}$. The patients were unresponsive to previous monotherapy 
Table 2 Important studies comparing the effects of the aliskiren/hydrochlorothiazide combination with other treatment regimens

\begin{tabular}{|c|c|c|c|}
\hline Reference & Patients (n) & Regimen & Results \\
\hline Villamil ${ }^{31}$ & 2776 & $\begin{array}{l}\text { Ali } 75-150-300 \\
\text { HCTZ 6.25-I2.5-25 } \\
\text { Ali-HCTZ all comb. except 300/6.25 }\end{array}$ & $\begin{array}{l}\text { Comparable doses of Ali and HCTZ } \\
\text { equally effective in lowering BP, comb; } \\
\text { achieved further BP reduction }\end{array}$ \\
\hline Jordan ${ }^{32}$ & $\begin{array}{l}489 \text { obese pts already } \\
\text { on HCTZ } 25 \mathrm{mg}\end{array}$ & $\begin{array}{l}\text { Ali-HCTZ 300/25 } \\
\text { Irb-HCTZ 300/25 } \\
\text { Aml-HCTZ 10/25 } \\
\text { HCTZ } 25\end{array}$ & $\begin{array}{l}\text { All combinations equally effective in } \\
\text { lowering BP and better than HCTZ alone; } \\
\text { Aml-HCTZ less tolerable due to edema, } \\
\text { hypokalemia }\end{array}$ \\
\hline Duprez $^{45}$ & $\begin{array}{l}901 \text { elderly pts } \\
(>65 \text { years })\end{array}$ & $\begin{array}{l}\text { Ali } 150 \rightarrow 300 \\
\text { Ramipril } 5 \rightarrow 10 \\
\text { Add-on HCTZ } 25 \text { after } 12 \text { weeks } \\
\text { and Aml } 10 \mathrm{mg} \text { after } 22 \text { weeks, if needed }\end{array}$ & $\begin{array}{l}\text { Ali group achieved target BP with the } \\
\text { addition of fewer drugs }\end{array}$ \\
\hline Strasser ${ }^{55}$ & $\begin{array}{l}\text { I83 pts with severe hypertension } \\
(>180 / 110 \mathrm{mmHg})\end{array}$ & $\begin{array}{l}\text { Ali } 150 \rightarrow 300 \\
\text { Lis } 20 \rightarrow 40 \\
\text { Add-on HCTZ } 25 \text { as needed }\end{array}$ & $\begin{array}{l}\text { Ali and Lis equally effective in lowering } \\
\text { BP, HCTZ addon in similar number of pts } \\
\text { in both groups needed }\end{array}$ \\
\hline Nickenig ${ }^{46}$ & $\begin{array}{l}880 \text { pts unresponsive to } \\
\text { Ali } 300 \text { alone }\end{array}$ & $\begin{array}{l}\text { Single-pill Ali-HCTZ } 300 / 12.5 \text { or } \\
300 / 25 \text { versus Ali } 300 \text { alone }\end{array}$ & $\begin{array}{l}\text { Single-pill comb more effective in BP } \\
\text { lowering than monotherapy, similarly well } \\
\text { tolerated }\end{array}$ \\
\hline Blumenstein ${ }^{47}$ & $\begin{array}{l}722 \text { pts unresponsive to } \\
\text { HCTZ } 25 \text { alone }\end{array}$ & $\begin{array}{l}\text { Single-pill Ali-HCTZ I50/25 or 300/25 } \\
\text { versus HCTZ } 25 \text { alone }\end{array}$ & $\begin{array}{l}\text { Single-pill more efficient in lowering } \\
\text { BP than monotherapy, similarly well } \\
\text { tolerated, less hypokalemia with the } \\
\text { single-pill combination }\end{array}$ \\
\hline
\end{tabular}

Note: Arrows indicate uptitration of the drug from the initial to the final dose.

Abbreviations: Ali, aliskiren; Aml, amlodipine; BP, blood pressure; HCTZ, hydrochlorothiazide; Irb, irbesartan; Lis, lisinopril; pts, patients.

with hydrochlorothiazide. Addition of aliskiren led to a significant reduction of blood pressure compared with a placebohydrochlorothiazide combination after eight weeks of treatment. Interestingly, the regimens including irbesartan $300 \mathrm{mg}$ and amlodipine $10 \mathrm{mg}$ had similar antihypertensive effects to those of the aliskiren-hydrochlorothiazide combination. However, the amlodipine-hydrochlorothiazide combination was less well tolerated as a result of an increased rate of peripheral edema. Plasma renin activity was, as expected, lower in the regimens including aliskiren, while the risk of hypokalemia was highest in the amlodipine-hydrochlorothiazide group. ${ }^{32}$

Aliskiren was compared with ramipril-based regimens in another study including 901 elderly ( $>65$ years) hypertensive patients. Aliskiren at a starting dose of $150 \mathrm{mg}$ and uptitrated to $300 \mathrm{mg}$ was compared with ramipril $5 \mathrm{mg}$ uptitrated to $10 \mathrm{mg}$ daily. If target blood pressure was not reached after 12 weeks, up to $25 \mathrm{mg}$ of hydrochlorothiazide and, after 22 weeks, up to $10 \mathrm{mg}$ of amlodipine were added to both regimens. Regimens based on aliskiren led to higher rates of blood pressure control. At week 36, fewer patients on the aliskiren-based regimen required addon treatment with hydrochlorothiazide or amlodipine compared with the ramipril regimens. Furthermore, lower rates of cough was reported for the aliskiren group. ${ }^{45}$

Two further studies have investigated single-pill combinations containing aliskiren. Nickenig et al examined treatment with a combination of aliskiren-hydrochlorothiazide
$300 / 12.5 \mathrm{mg}$ or $300 / 25 \mathrm{mg}$ in 880 hypertensive patients nonresponsive to aliskiren $300 \mathrm{mg}$ alone (mean sitting diastolic blood pressure $90-110 \mathrm{mmHg}$ after four weeks of treatment). Rates of blood pressure control were significantly higher using the single-pill regimens ( $60.2 \%$ for the $300 / 25 \mathrm{mg}$ and $57.9 \%$ for the $300 / 12.5 \mathrm{mg}$ doses) than with aliskiren alone $(40.9 \%)$. The tolerability of the single pill was similar to that of aliskiren alone. ${ }^{46}$ In another study, Blumenstein et al compared the single-pill combinations of aliskiren-hydrochlorothiazide $150 / 25 \mathrm{mg}$ and $300 / 25 \mathrm{mg}$ with hydrochlorothiazide $25 \mathrm{mg}$ monotherapy in 722 patients previously treated with hydrochlorothiazide $25 \mathrm{mg}$ without having reached their target blood pressure. Both combinations were superior to hydrochlorothiazide monotherapy in reducing blood pressure. Fifty-eight percent of patients on the $300 / 25 \mathrm{mg}$ combination reached their target blood pressure versus $49 \%$ for the $150 / 25 \mathrm{mg}$ combination and $26 \%$ for hydrochlorothiazide $25 \mathrm{mg}$ monotherapy. Tolerability was similar in all groups, although hypokalemia was higher in the hydrochlorothiazide monotherapy group. ${ }^{47}$

\section{Safety and tolerability}

It is important for a drug to be safe and well tolerated by patients. Overall, aliskiren in combination with hydrochlorothiazide was shown to be safe in various studies. Adverse effects were mild, and commonly included 
headache (6\% versus $9 \%$ with placebo), dizziness $(2.5 \%$ versus $1 \%$ with placebo), diarrhea (1.8\% versus $0.5 \%$ with placebo), and flu-like symptoms (2.5\% versus $1.6 \%$ with placebo). ${ }^{31,32,40,46,48}$ Hypokalemia was significantly lower for the aliskiren-hydrochlorothiazide combination (1\%-2\% in the combinations with hydrochlorothiazide $12.5 \mathrm{mg}$ and $2 \%-3 \%$ in those with hydrochlorothiazide $25 \mathrm{mg}$ ) compared with hydrochlorothiazide alone (4\%-5\%) and slightly higher than in the placebo groups (1\%) and for the irbesartan-hydrochlorothiazide combination, especially in obese patients. ${ }^{31,32}$ Cough ( $1.5 \%$ versus $0.5 \%$ with placebo) presents less often than with ACE inhibitors and at a similar rate to that with ARBs. Hyperkalemia might be of concern, especially when aliskiren is used in conjunction with an ACE inhibitor or an ARB.

\section{Cost comparison with other first-line treatments}

An important aspect of antihypertensive drugs is their costeffectiveness. Aliskiren both alone and in combination with hydrochlorothiazide is able to reduce blood pressure to a similar degree as ACE inhibitors and ARBs (and their combinations with hydrochlorothiazide). Treatment costs vary widely from country to country. However, the cost of aliskiren is similar to that of ARBs and much higher than that of the older ACE inhibitors. With ARBs and aliskiren being as effective in lowering blood pressure as the ACE inhibitors and slightly better tolerated than the latter, treatment with an ACE inhibitor seems to be the logical first choice, with ARBs and aliskiren reserved for selected patients who cannot tolerate ACE inhibitors. Interestingly, aliskiren seems also to be as effective as hydrochlorothiazide and amlodipine, which are much cheaper treatment options. However, the tolerability of hydrochlorothiazide and amlodipine is inferior to that of aliskiren and they tend to have more side effects, including electrolyte disorders and edema.

\section{Effects of aliskiren on cardiovascular disease outcomes}

Of great importance is the effect of aliskiren on outcomes in patients with cardiovascular disease and end organ damage. Several preclinical studies have demonstrated favorable effects of aliskiren on cardiac hypertrophy, myocardial function and remodeling after myocardial infarction, and kidney failure. ${ }^{49,50}$ However, there are no data available as yet showing a benefit of aliskiren in reducing cardiovascular mortality. Most studies have investigated the effects of aliskiren on biomarkers or surrogate outcomes, while large prospective trials with mortality outcomes are expected to be completed in the near future.

The ALiskiren Observation of Heart Failure Study (ALOFT) investigated the effects of add-on treatment with aliskiren $150 \mathrm{mg}$ in 302 patients with stable heart failure (New York Heart Association II-IV) and hypertension, previously on ACE inhibitors or ARBs and beta-blockers. ${ }^{51}$ Addon aliskiren therapy significantly reduced the levels of $\mathrm{N}$-terminal pro brain natriuretic peptide, without additional risk of hyperkalemia, hypotension, or worsening renal function. In the Aliskiren in Left Ventricular Hypertrophy (ALLAY) study, treatment with aliskiren $300 \mathrm{mg}$ was noninferior to losartan $100 \mathrm{mg}$ in reducing left ventricular hypertrophy. ${ }^{52}$ However, in the recently presented ASPIRE (Aliskiren Study in Post-MI Patients to Reduce Remodeling) trial, aliskiren titrated to $300 \mathrm{mg}$ on top of an ACE inhibitor or an ARB failed to show any improvement in myocardial remodeling after acute myocardial infarction and left ventricular ejection fraction below $45 \%$, while an increase in adverse effects was observed. ${ }^{53}$ In the AVOID trial (Aliskiren in the eValuation of prOteinuria in Diabetes), 599 hypertensive diabetics with diabetic nephropathy and proteinuria were treated with aliskiren $300 \mathrm{mg}$ or placebo on top of previous treatment with $100 \mathrm{mg}$ losartan. ${ }^{54}$ Aliskiren reduced the albumin creatinine ratio by $20 \%$ compared with placebo after six months of treatment.

The findings of two large-scale trials, ie, ALTITUDE (Aliskiren Trial In Type 2 Diabetes Using Cardio-Renal Disease Endpoints) and ATMOSPHERE (Aliskiren Trial to Minimize OutcomeS in Patients with Heart FailuRE) are awaited with great interest. The aim of ALTITUDE is to examine whether aliskiren is able to reduce cardiovascular and renal morbidity and mortality when used on top of pre-existing therapy with an ACE inhibitor or an ARB in high-risk patients with Type 2 diabetes. ATMOSPHERE is investigating the effects of aliskiren on cardiovascular death and rehospitalization in patients with chronic heart failure.

\section{Lessons from the ACCOMPLISH trial}

ACE inhibitors and ARBs have been shown to reduce cardiovascular morbidity and mortality in many different patient groups and are considered first-line drugs in such patients. It is therefore intriguing to suggest, in expectation of large outcome trials, that aliskiren is also going to show similar results. However, cardiovascular patients tend to need more than one drug to control their hypertension. Therefore, it would be interesting to find an effective partner drug for 
the RAAS inhibitors. Hydrochlorothiazide has been the standard add-on drug when monotherapy is inadequate. The recent ACCOMPLISH trial (Avoiding Cardiovascular Events in Combination Therapy in Patients Living with Systolic Hypertension) has shown that the combination of benazepril (an ACE inhibitor) and amlodipine prevents cardiovascular events more effectively than the combination of benazepril and hydrochlorothiazide. Therefore, one could speculate that amlodipine might be a more appropriate partner for aliskiren than hydrochlorothiazide in patients with hypertension and no signs of volume overload, where a diuretic would be more appropriate.

\section{Conclusion}

Only $30 \%$ of hypertensive patients reach target blood pressure with monotherapy, and $70 \%$ require one or more additional agents. Fixed-drug combinations can improve patient compliance, and their use is supported by current guidelines for treatment of arterial hypertension. The combination of a RAAS inhibitor with hydrochlorothiazide is effective and reasonable because it potentiates the antihypertensive effects and lowers side effects of the component drugs. Aliskiren and its combination with hydrochlorothiazide appear to be as effective as ARBs and ACE inhibitors in the treatment of uncomplicated hypertension and as safe and tolerable as the ARBs and slightly better than the ACE inhibitors. However, there are still no clinical studies showing a mortality benefit for aliskiren or reduction of end organ damage, as are available for the ACE inhibitors and ARBs. Furthermore, the effects of reduced plasma renin activity and increased plasma renin concentration induced by aliskiren remain to be shown in large prospective studies and, while there are interesting experimental data, their clinical importance remains unclear.

Finally, it is intriguing to consider the findings of the recent ACCOMPLISH study and speculate that the combination of aliskiren with a calcium antagonist might be an even better combination, especially for patients with metabolic disorders and high cardiovascular risk.

\section{Disclosure}

The authors report no conflicts of interest in this work.

\section{References}

1. Kearney PM, Whelton M, Reynolds K, Muntner P, Whelton PK, He J. Global burden of hypertension: Analysis of worldwide data. Lancet. 2005;365(9455):217-223.

2. Whitworth JA. 2003 World Health Organization (WHO)/International Society of Hypertension (ISH) statement on management of hypertension. J Hypertens. 2003;21(11):1983-1992.
3. Mancia G, Laurent S, Agabiti-Rosei E, et al. Reappraisal of European guidelines on hypertension management: A European Society of Hypertension Task Force document. Blood Press. 2009;18(6):308-347.

4. Chobanian AV, Bakris GL, Black HR, et al. Seventh report of the Joint National Committee on Prevention, Detection, Evaluation, and Treatment of High Blood Pressure. Hypertension. 2003;42(6):1206-1252.

5. Wang YR, Alexander GC, Stafford RS. Outpatient hypertension treatment, treatment intensification, and control in Western Europe and the United States. Arch Intern Med. 2007;167(2):141-147.

6. Wolf-Maier K, Cooper RS, Kramer H, et al. Hypertension treatment and control in five European countries, Canada, and the United States. Hypertension. 2004;43(1):10-17.

7. Wald DS, Law M, Morris JK, Bestwick JP, Wald NJ. Combination therapy versus monotherapy in reducing blood pressure: Meta-analysis on 11,000 participants from 42 trials. Am J Med. 2009;122(3):290-300.

8. Materson BJ, Reda DJ, Cushman WC, et al. Single-drug therapy for hypertension in men. A comparison of six antihypertensive agents with placebo. The Department of Veterans Affairs Cooperative Study Group on Antihypertensive Agents. N Engl J Med. 1993;328(13):914-921.

9. Gradman AH, Basile JN, Carter BL, et al. Combination therapy in hypertension. J Am Soc Hypertens. 2010;4(2):90-98.

10. Gupta AK, Arshad S, Poulter NR. Compliance, safety, and effectiveness of fixed-dose combinations of antihypertensive agents: A meta-analysis. Hypertension. 2010;55(2):399-407.

11. Dzau V. The cardiovascular continuum and renin-angiotensin-aldosterone system blockade. J Hypertens Suppl. 2005;23(1):S9-S17.

12. Conlin PR, Gerth WC, Fox J, Roehm JB, Boccuzzi SJ. Four-year persistence patterns among patients initiating therapy with the angiotensin II receptor antagonist losartan versus other artihypertensive drug classes. Clin Ther. 2001;23(12):1999-2010.

13. Waeber B. Combination therapy with ACE inhibitors/angiotensin II receptor antagonists and diuretics in hypertension. Expert Rev Cardiovasc Ther. 2003;1(1):43-50.

14. Ferrario CM, Strawn WB. Role of the renin-angiotensin-aldosterone system and proinflammatory mediators in cardiovascular disease. Am J Cardiol. 2006;98(1):121-128.

15. Wollert KC, Drexler H. The renin-angiotensin system and experimental heart failure. Cardiovasc Res. 1999;43(4):838-849.

16. Derkx FH, Schalekamp MA. Human prorenin: Pathophysiology and clinical implications. Clin Exp Hypertens A. 1988;10(6):1213-1225.

17. Danser AH, Deinum J. Renin, prorenin and the putative (pro)renin receptor. Hypertension. 2005;46(5):1069-1076.

18. Tschope C, Schultheiss HP, Walther T. Multiple interactions between the renin-angiotensin and the kallikrein-kinin systems: Role of ACE inhibition and AT1 receptor blockade. J Cardiovasc Pharmacol. 2002; 39(4):478-487.

19. Hoogwerf BJ. Renin-angiotensin system blockade and cardiovascular and renal protection. Am J Cardiol. 2010;105 Suppl 1:30A-35A.

20. van den Meiracker AH, Man in 't Veld AJ, Admiraal PJ, et al. Partial escape of angiotensin converting enzyme (ACE) inhibition during prolonged ACE inhibitor treatment: Does it exist and does it affect the antihypertensive response? J Hypertens. 1992;10(8):803-812.

21. Sureshkumar KK. Renin inhibition with aliskiren in hypertension: Focus on aliskiren/hydrochlorothiazide combination therapy. Vasc Health Risk Manag. 2008;4(6):1205-1220.

22. Kim S, Iwao H. Molecular and cellular mechanisms of angiotensin II-mediated cardiovascular and renal diseases. Pharmacol Rev. 2000; 52(1):11-34.

23. Vaidyanathan S, Jarugula V, Dieterich HA, Howard D, Dole WP. Clinical pharmacokinetics and pharmacodynamics of aliskiren. Clin Pharmacokinet. 2008;47(8):515-531.

24. Azizi M, Webb R, Nussberger J, Hollenberg NK. Renin inhibition with aliskiren: Where are we now, and where are we going? J Hypertens. 2006;24(2):243-256.

25. Waldmeier F, Glaenzel U, Wirz B, et al. Absorption, distribution, metabolism, and elimination of the direct renin inhibitor aliskiren in healthy volunteers. Drug Metab Dispos. 2007;35(8):1418-1428. 
26. Nussberger J, Wuerzner G, Jensen C, Brunner HR. Angiotensin II suppression in humans by the orally active renin inhibitor aliskiren (SPP100): Comparison with enalapril. Hypertension. 2002;39(1):E1-E8.

27. Azizi M, Menard J, Bissery A, et al. Pharmacologic demonstration of the synergistic effects of a combination of the renin inhibitor aliskiren and the $\mathrm{AT}_{1}$ receptor antagonist valsartan on the angiotensin II-renin feedback interruption. J Am Soc Nephrol. 2004;15(12):3126-3133.

28. Danser AH. (Pro)renin receptors: Are they biologically relevant? Curr Opin Nephrol Hypertens. 2009;18(1):74-78.

29. Andersen K, Weinberger MH, Constance CM, et al. Comparative effects of aliskiren-based and ramipril-based therapy on the renin system during long-term (6 months) treatment and withdrawal in patients with hypertension. J Renin Angiotensin Aldosterone Syst. 2009;10(3):157-167.

30. Ernst ME, Moser M. Use of diuretics in patients with hypertension. N Engl J Med. 2009;361(22):2153-2164.

31. Villamil A, Chrysant SG, Calhoun D, et al. Renin inhibition with aliskiren provides additive antihypertensive efficacy when used in combination with hydrochlorothiazide. J Hypertens. 2007;25(1):217-226.

32. Jordan J, Engeli S, Boye SW, le Breton S, Keefe DL. Direct renin inhibition with aliskiren in obese patients with arterial hypertension. Hypertension. 2007;49(5):1047-1055.

33. Westermann D, Schmieder R, Schultheiss HP, Tschope C. Renin inhibitors, clinical experience. J Mol Med. 2008;86(6):691-695.

34. Pinto R, Gradman AH. Direct renin inhibition: An update. Curr Hypertens Rep. 2009;11(6):456-462.

35. Musini VM, Fortin PM, Bassett K, Wright JM. Blood pressure lowering efficacy of renin inhibitors for primary hypertension. Cochrane Database Syst Rev. 2008(4):CD007066.

36. Stanton AV, Gradman AH, Schmieder RE, Nussberger J, Sarangapani R, Prescott MF. Aliskiren monotherapy does not cause paradoxical blood pressure rises: Meta-analysis of data from 8 clinical trials. Hypertension. 2010;55(1):54-60.

37. Kushiro T, Itakura H, Abo Y, Gotou H, Terao S, Keefe DL. Aliskiren, a novel oral renin inhibitor, provides dose-dependent efficacy and placebo-like tolerability in Japanese patients with hypertension. Hypertens Res. 2006;29(12):997-1005.

38. Gradman AH, Schmieder RE, Lins RL, Nussberger J, Chiang Y, Bedigian MP. Aliskiren, a novel orally effective renin inhibitor, provides dose-dependent antihypertensive efficacy and placebo-like tolerability in hypertensive patients. Circulation. 2005;111(8):1012-1018.

39. Stanton A, Jensen C, Nussberger J, O’Brien E. Blood pressure lowering in essential hypertension with an oral renin inhibitor, aliskiren. Hypertension. 2003;42(6):1137-1143.

40. Pool JL, Schmieder RE, Azizi M, et al. Aliskiren, an orally effective renin inhibitor, provides antihypertensive efficacy alone and in combination with valsartan. Am J Hypertens. 2007;20(1):11-20.

41. Ernst ME, Carter BL, Goerdt CJ, et al. Comparative antihypertensive effects of hydrochlorothiazide and chlorthalidone on ambulatory and office blood pressure. Hypertension. 2006;47(3):352-358.
42. Onuigbo MA. ALLHAT findings revisited in the context of subsequent analyses, other trials, and meta-analyses. Arch Intern Med. 2009;169(19):1810.

43. Messerli FH, Bangalore S, Julius S. Risk/benefit assessment of betablockers and diuretics precludes their use for first-line therapy in hypertension. Circulation. 2008;117(20):2706-2715.

44. Calhoun DA, Villamil AS, Chrysant SG, Schober B, Fang H, Zhang J. Antihypertensive efficacy of aliskiren/hydrochlorothiazide (HCT) combinations in patients with stage 2 hypertension: Subgroup analysis of a randomized, double-blind, factorial trial. Hypertension. 2008;52(4):E97.

45. Duprez DA, Munger MA, Botha J, Keefe DL, Charney AN. Aliskiren for geriatric lowering of systolic hypertension: A randomized controlled trial. J Hum Hypertens. 2010;24(9):600-608.

46. Nickenig G, Simanenkov V, Lembo G, et al. Efficacy of aliskiren/hydrochlorothiazide single-pill combinations in aliskiren non-responders. Blood Press Suppl. 2008;2:31-40.

47. Blumenstein M, Romaszko J, Calderon A, et al. Antihypertensive efficacy and tolerability of aliskiren/hydrochlorothiazide (HCT) single-pill combinations in patients who are non-responsive to HCT $25 \mathrm{mg}$ alone. Curr Med Res Opin. 2009;25(4):903-910.

48. Weir MR, Bush C, Anderson DR, Zhang J, Keefe D, Satlin A. Antihypertensive efficacy, safety, and tolerability of the oral direct renin inhibitor aliskiren in patients with hypertension: A pooled analysis. J Am Soc Hypertens. 2007;1(4):264-277.

49. Muller DN, Derer W, Dechend R. Aliskiren - mode of action and preclinical data. J Mol Med. 2008;86(6):659-662.

50. Westermann D, Riad A, Lettau O, et al. Renin inhibition improves cardiac function and remodeling after myocardial infarction independent of blood pressure. Hypertension. 2008;52(6):1068-1075.

51. McMurray JJ, Pitt B, Latini R, et al. Effects of the oral direct renin inhibitor aliskiren in patients with symptomatic heart failure. Circ Heart Fail. 2008;1(1):17-24.

52. Solomon SD, Appelbaum E, Manning WJ, et al. Effect of the direct renin inhibitor aliskiren, the angiotensin receptor blocker losartan, or both on left ventricular mass in patients with hypertension and left ventricular hypertrophy. Circulation. 2009;119(4):530-537.

53. Jacobshagen C, Westermann D, Holubarsch C, Bohm M. Hotline update of clinical trials and registries presented at the American College of Cardiology Congress 2010: ACCORD, INVEST, NAVIGATOR, RACE II, SORT OUT III, CSP-474, DOSE, ASPIRE and more. Clin Res Cardiol. 2010;99(6):337-344.

54. Parving HH, Persson F, Lewis JB, Lewis EJ, Hollenberg NK. Aliskiren combined with losartan in type 2 diabetes and nephropathy. $N$ Engl J Med. 2008;358(23):2433-2446.

55. Strasser RH, Puig JG, Farsang C, Croket M, Li J, van Ingen H. A comparison of the tolerability of the direct renin inhibitor aliskiren and lisinopril in patients with severe hypertension. J Hum Hypertens. 2007;21(10):780-787.
Integrated Blood Pressure Control

\section{Publish your work in this journal}

Integrated Blood Pressure Control is an international, peer-reviewed open-access journal focusing on the integrated approach to managing hypertension and risk reduction. Treating the patient and comorbidities together with diet and lifestyle modification and optimizing healthcare resources through a multidisciplinary team approach constitute key

\section{Dovepress}

features of the journal. This journal is indexed on American Chemical Society's Chemical Abstracts Service (CAS). The manuscript management system is completely online and includes a very quick and fair peerreview system, which is all easy to use. Visit http://www.dovepress.com/ testimonials.php to read real quotes from published authors. 